\title{
Altas Capacidades em meios Vulneráveis: produções acadêmicas brasileiras e
}

\section{internacionais}

\author{
High capacities in vulnerable environments: Brazilian and international academic productions \\ Altas capacidades en entornos vulnerables: producciones académicas brasileñas e internacionales
}

Recebido: 29/12/2020 | Revisado: 30/12/2020 | Aceito: 08/01/2021 | Publicado: 09/01/2021

\author{
Amanda Rodrigues de Souza Colozio \\ ORCID: https://orcid.org/0000-0003-3788-4084 \\ Universidade Federal de São Carlos, Brasil \\ Universidad de La Laguna, Espanha \\ E-mail: amandardesouza@ hotmail.com \\ Rosemeire de Araújo Rangni \\ ORCID: https://orcid.org/0000-0002-8752-9745 \\ Universidade Federal de São Carlos, Brasil \\ E-mail: rose.rangni@uol.com.br \\ África Borges \\ ORCID https://orcid.org/0000-0001-8267-4401 \\ Universidad de La Laguna, Espanha \\ E-mail: afri.borges@ull.edu.es
}

\begin{abstract}
Resumo
Reconhecer altas capacidades em classes sociais menos favorecidas é um desafio porque crianças em condições de vulnerabilidade podem ser deixadas à margem nos meios sociais e educacionais. Definiu-se como objetivo do artigo verificar em bases de dados brasileiras e internacionais se há produções científicas sobre altas capacidades em meios vulneráveis. Foi realizada uma revisão sistemática das produções nas bases de dados: Scientific Eletronic Library Online (Scielo); Periódicos Eletrônicos em Psicologia (PePSIC); Revista Educação Especial, e por fim na EBSCO host, aplicando o filtro de pesquisa: Academic Search Complete, Education Resources Information Center (ERIC) e Psycarticles. Como resultados, obteve-se 4 (quatro) artigos brasileiros e 14 (quatorze) artigos internacionais. As produções encontradas se relacionam a temas diversos, tais como: pobreza, encarcerados ou que cometem atos infracionais, situação de rua e vulnerabilidade escolar ou em risco social, sendo que a temática mais relatada nas pesquisas foi altas capacidades e pobreza. Por meio das buscas realizadas, infere-se, que altas capacidades e vulnerabilidade são temas ainda pouco estudados, o que pode levar a crer em uma falta de identificação e atendimento a essas crianças, jovens e adultos de meios vulneráveis e, consequente resultando numa perda de seus talentos.
\end{abstract}

Palavras-chave: Educação especial; Altas capacidades; Altas habilidades; Superdotação; Vulnerabilidade.

\begin{abstract}
Recognizing high abilities in less favored social classes is a challenge because children in vulnerable conditions can be left out in social and educational settings. The objective of the article was to verify in Brazilian and international databases whether there are scientific productions about high abilities in vulnerable environments. A systematic review of the productions was carried out on the following databases: Scientific Eletronic Library Online (Scielo); Periódicos Eletrônicos em Psicologia (PePSIC); Revista Educação Especial, and finally at EBSCO host, applying the search filter: Academic Search Complete, Education Resources Information Center (ERIC) and Psycarticles. As a result, it was obtained, 4 (four) Brazilian articles and 14 (fourteen) international articles. The productions found are related to several themes, such as: poverty, prisoners or those who commit infractions, homelessness and school vulnerability or at social risk, and the most reported theme in the research was high capacities and poverty. Based on the researches, could be inferred that high abilities and vulnerability are themes still poorly studied, which may lead to believe in a lack of identification and attention for these children, adolescents and adults from vulnerable environments and, consequently, resulting in a loss of his talents.
\end{abstract}

Keywords: Special education; High capacities; High skills; Giftedness; Vulnerability.

\section{Resumen}

Reconocer las altas capacidades en las clases sociales menos favorecidas es un desafío porque niños en condiciones vulnerables pueden quedar fuera de los entornos sociales y educativos. El objetivo del presente artículo fue verificar en bases de datos brasileñas e internacionales si existen producciones científicas sobre las altas capacidades en contextos vulnerables. Se realizó una revisión sistemática de las producciones en las bases de datos: Scientific Eletronic Library Online (Scielo); Periódicos Eletrônicos em Psicologia (PePSIC); Revista Educação Especial, y finalmente en el EBSCO host, aplicando el filtro de búsqueda: Academic Search Complete, Education Resources 
Information Center (ERIC) y Psycarticles. Como resultados, se obtuvieron 4 (cuatro) artículos brasileños y 14 (catorce) artículos internacionales. Las producciones encontradas están relacionadas con diversos temas, tales como: pobreza, presos o infractores, desamparo y vulnerabilidad escolar o en riesgo social, y el tema más reportado en la investigación fue altas capacidades y pobreza. A través de las búsquedas realizadas, se infiere que las altas capacidades y la vulnerabilidad aún son temas poco estudiados, lo que puede llevar a creer en una falta de identificación y atención a estos niños, jóvenes y adultos de entornos vulnerables y, consecuentemente, resultando en la pérdida de sus talentos.

Palabras clave: Educación especial; Altas capacidades; Altas habilidades; Superdotación; Vulnerabilidad.

\section{Introdução}

Para o Decreto $\mathrm{n}^{\mathrm{o}}$ 10.502, de 30 de setembro de 2020, que institui a Política Nacional de Educação Especial: Equitativa, Inclusiva e com Aprendizado ao Longo da Vida, alunos com altas capacidades apresentam desenvolvimento ou potencial elevado em qualquer área de domínio, isolada ou combinada, criatividade e envolvimento com as atividades escolares. As áreas de manifestações das altas capacidades seriam: intelectual, acadêmica, liderança, psicomotricidade e artes (Brasil, 2020).

Nessa perspectiva, Simonetti, Almeida e Guenther (2010, p.45) assinalam que “[...]não se pretendendo equalizar expressões como capacidade elevada, dotação e talento, aceitaremos com alguma facilidade que todas elas se reportam a habilidades cognitivas e a desempenhos superiores", desta forma, o termo altas capacidades é usado na presente pesquisa, para se referir ao público com altas habilidades ou superdotação . Para além, uma das grandes barreiras para identificar esse público em específico, é que não há consenso de uma definição ou uma terminologia para o sujeito com altas capacidades, o que propiciaria identificá-los e atendê-los mais adequadamente, levando-se em conta o contexto brasileiro com sua complexidade de diferenças sociais e econômicas.

Winner (1998) pontua que os mitos acerca dessa população podem prejudicar sua identificação e atendimento, sendo que um deles pontuado pela autora, seria que a alta capacidade é inata ou é produto do meio social. Tendo a premissa que as altas capacidades nasceriam com o sujeito, ou seja, ele seria ou não uma pessoa com altas capacidades apenas pelos seus genes. E por outro lado, o mito de que seria fruto apenas do meio social, ou seja, que ao nascer em um lugar com boas condições de estudo e estímulo poderá ter suas habilidades desenvolvidas e desenvolver as altas capacidades. Ambos os mitos prejudicam a identificação das altas capacidades, especialmente em pessoas mais vulneráveis, pois ao olhar apenas para o ambiente enriquecido, por exemplo, excluiria possibilidades de encontrar altas capacidades em ambientes desfavorecidos ou vulneráveis, e pensar apenas no gene, excluiria a possibilidade de encontrar crianças em meios pobres por não serem visto como "bemsucedidos" ou muito inteligentes.

Essas diferenças voltam-se, evidentemente, ao sujeito vulnerável. Sobre esse aspecto, McCluskey (2016) pontua que quando se trata de uma população marginalizada há sérios problemas de definição terminológica, sem chegar a um consenso, sobretudo porque podem ser chamados de pessoas em riscos, vulneráveis, marginalizadas, em desvantagem, menos favorecidos, desconectadas, não engajadas, sem privilégios ou resistentes a relacionamentos.

Neste sentido, Landau (2002) sugere que a relevância de reconhecer altas capacidades em classes sociais menos favorecidas e de compreender o "culturalmente menos privilegiado", e, ela afirma que vem de uma combinação de baixa renda, tamanho de família e baixo nível de instrução dos pais. Crianças nessas condições podem ser ignoradas e em seus caminhos podem utilizar sua inteligência em atuações destrutivas e antissociais. A referida autora assevera que, deve-se trabalhar na educação para as altas capacidades de pessoas em meios socialmente desprovidos, incentiva-las a brincar com a aprendizagem, adotar valores positivos, estimular a criatividade, permitindo-as que se conscientize de suas habilidades e fortaleça sua autoestima.

Becker (2014) propõe uma reflexão sobre quais das características e comportamentos se repetem em crianças em 
desenvolvimento de qualquer cultura e nível socioeconômico e que podem ser encontradas naquelas que nascem e habitam ambientes extremamente carentes. Pontuando que crianças e jovens que vivem em famílias desestruturadas com desemprego familiar, pouca ou nenhuma educação formal, falta de moradia e infraestrutura ambiental e que ao superarem seus desafios, são denominados de resilientes, questionando se "os chamados resilientes não serão pessoas com talentos especiais que superaram as desvantagens ambientais e sociais usando seu potencial intelectual, afetivo e criativo?” (Becker, 2014, p. 693).

Com esse posicionamento em mente, Cupertino (2008) assinala que sem estímulo a criança com alas capacidades ignora seu potencial e pode apresentar inadequação, como também afirma que, "num país pleno de carências, não se considera relevante o atendimento diferenciado a quem já foi privilegiado com um dom especial. Os superdotados estão escondidos nas salas de aula comuns, como se seus talentos fossem invisíveis" (Cupertino, 2008, p.10).

A partir desses apontamentos, a pesquisa que suscita este artigo parte de que pessoas vulneráveis são aquelas que estão em situação de acolhimento institucional, em condição de pobreza e marginalização ou reclusão. $\mathrm{O}$ acolhimento institucional é uma medida de caráter protetiva e aplicável na Lei Federal no 8069/1990 (Brasil, 2015), no Estatuto da Criança e do Adolescente (ECA), sempre que os direitos ali contidos forem ameaçados ou violados.

Desse modo, empreendeu-se o seguinte questionamento para a construção do estudo: é possível encontrar produções sobre altas capacidades em meios vulneráveis em bases acadêmicas brasileiras e internacionais?

Tendo essa questão em vista, o objetivo foi verificar e analisar artigos científicos sobre altas capacidades em meios vulneráveis por meio de uma busca em bancos de dados.

\section{Metodologia}

Para o desenvolvimento do trabalho foi realizada uma revisão sistemática das produções acadêmicas em bases de dados brasileiras e internacionais. Segundo Sampaio e Mancini (2007), revisões sistemáticas são uma forma de pesquisa que utiliza como fonte de dados a literatura sobre determinado tema, sendo que esse tipo de investigação disponibiliza um resumo das evidências relacionadas a uma estratégia de intervenção específica, mediante a aplicação de métodos explícitos e sistematizados de busca, apreciação crítica e síntese da informação selecionada.

Para sua execução, no contexto brasileiro, selecionaram-se três bases de dados, quais sejam: Scientific Eletronic Library Online (Scielo), Periódicos Eletrônicos em Psicologia (PePSIC) e Revista Educação Especial. A seleção de tais fontes justifica por haver possibilidades de possuírem artigos científicos na área pesquisada.

As bases de dados internacionais pesquisadas foram: EBSCO host, aplicando o filtro de pesquisa para: Academic Search Complete, Education Resources Information Center (ERIC), Psycarticles. Essa seleção se justifica porque é uma base de dados que possui uma abrangente coleção de conteúdo, incluindo a indexação de temas, textos completos e toda a coleção de bibliotecas da EBSCO Information Services.

Nos portais brasileiros, foi efetuada a busca por artigos, sem limitação de períodos temporais e sem limitação de idioma. Para tal se utilizou as seguintes palavras-chave isoladas e/ou combinadas: Altas Habilidades; Superdotação; Dotação; Talento; Sobresaliente; Sobredotado; Altas Capacidades; Giftedness; High ability; Talent; Instituições de acolhimento; Vulnerabilidade; Vulnerability; Foster Care . E, nas bases internacionais, foram utilizadas as seguintes palavras-chave isoladas e/ou combinadas: Giftedness; High ability; Talent; Vulnerability; Foster Care.

As buscas foram realizadas em julho de 2020. O critério para incluir os artigos foi que apresentasse inicialmente no título e no resumo altas habilidades/superdotação e/ou em situação de vulnerabilidade, em situação de acolhimento em instituições, ou mesmo, em situação de pobreza, marginalização e reclusão.

Para a demonstração dos resultados usou-se o modelo de fluxo de informação do PRISMA, que segundo Moher (2015, p.336) "o objetivo do PRISMA é ajudar os autores a melhorarem o relato de revisões sistemáticas e meta-análises". 
Para a análise dos dados encontrados se valeu da abordagem qualitativa, que segundo Minayo (2010) se ajustam melhor a investigações de grupos e segmentos delimitados e focalizados, de histórias sociais sob a ótica dos atores, de relações e para análises de discursos e de documentos.

Os caminhos percorridos na seleção dos artigos da revisão sistemática nas bases de dados são ilustrados na figura 1 e, após, são apresentados os resultados encontrados na Tabela 1 e 2, seguidos da discussão.

Figura 1. Resultados das Produções Encontradas em Bases de Dados.

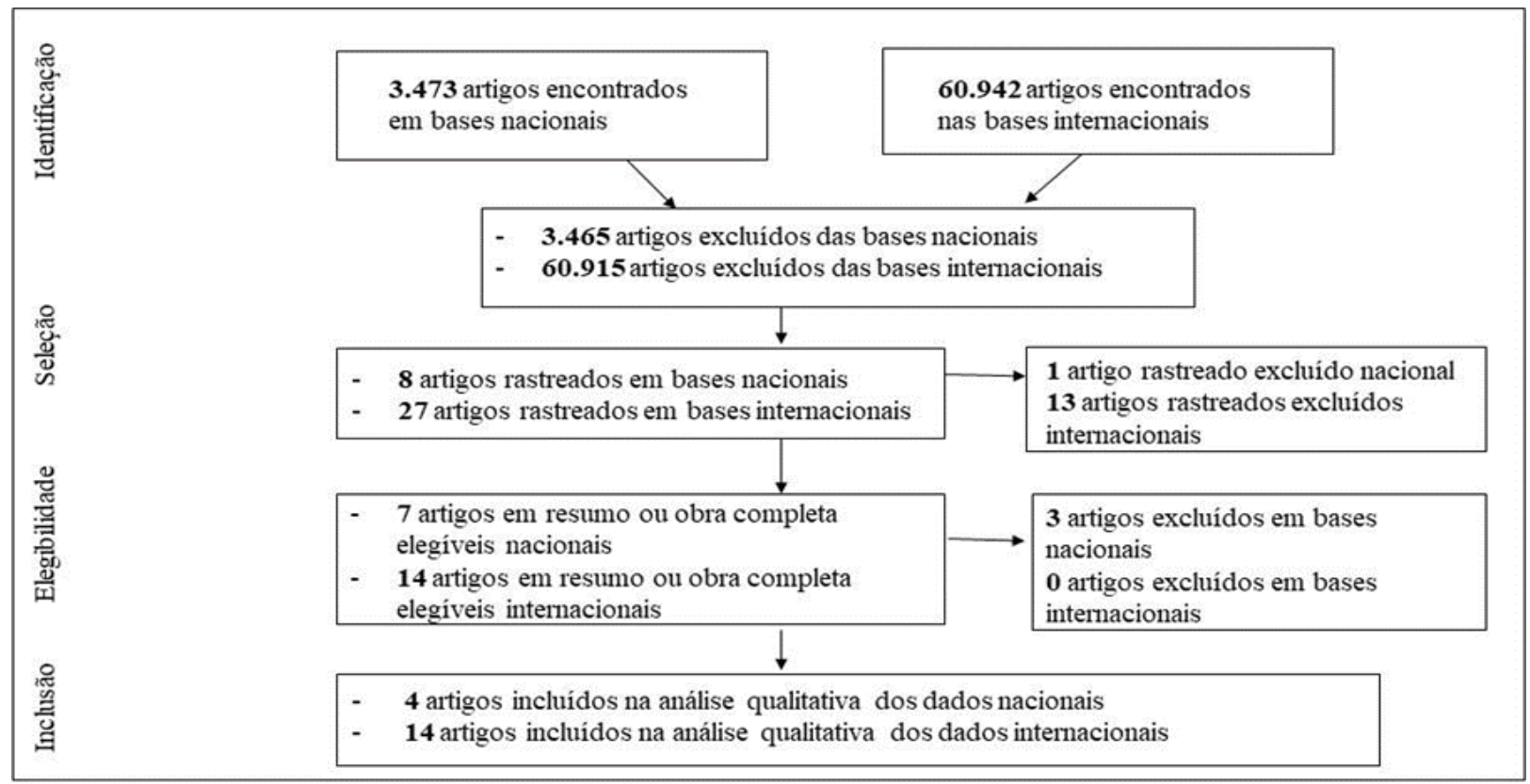

Fonte: Autores (2020).

Conforme pode ser observado, foi realizada uma extensa busca em bases de dados brasileiras e internacionais. Para a seleção dos artigos utilizou-se do modelo PRISMA: Identificação, Seleção, Elegibilidade e Inclusão. Desta forma, destaca-se que os artigos incluídos na pesquisa foram 4 (quatro) artigos brasileiros e 14 artigos internacionais. A abordagem dos artigos será apresentada em resultados e discussões.

\section{Resultados}

Os documentos incluídos nas bases brasileiras retornaram resultados do SCIELO e da Revista de Educação Especial, já na busca na PePSIC não resultou em artigos que estivessem nos critérios de inclusão da pesquisa. Cabe salientar que nas bases buscadas com os termos isolados obteve-se maior retorno de artigos do que na busca combinada de dois termos, como por exemplo, instituição de acolhimento e altas habilidades; a combinação para o propósito desta pesquisa. No entanto, retornaram em zero (0) resultados. É possível levantar a hipótese os dois temas não foram usados conjuntamente nas referências das produções.

Nas bases internacionais, importa mencionar que o termo talent foi o que mais resultou em artigos, seguido pelo termo giftedness e high ability, sugerindo que tais termos podem ser os mais usados para se referir ao público com altas capacidades, no âmbito internacional. A busca total entre termos isolados e combinados retornou em mais de 60.000 (sessenta mil) artigos com os filtros aplicados, salientando que dois termos giftdness e talent foram explorados apenas até a página 10 (dez) por possuírem extensos resultados, ao direcionar até 500 (quinhentos) artigos de cada busca terminológica. Foi possível perceber que internacionalmente a área das altas capacidades aparece com um número expressivo de pesquisas realizadas. Ressalta-se 
que, em algumas pesquisas houve acesso ao trabalho completo e, em outras, apenas ao resumo, devido à base EBSCO host não disponibilizar gratuidade para acesso a alguns artigos. Sendo assim, são apresentados na Tabela 1 os 4 (quatro) artigos nacionais e na Tabela 2 os 14 (quatorze) internacionais incluídos por relevância.

A seguir são expostos os resultados da busca em bases de dados brasileiras:

Quadro 1. Artigos Encontrados - Bases Brasileiras.

\begin{tabular}{|c|c|c|c|}
\hline Título & Autor(es) & Objetivo(s) & Participante(s) \\
\hline $\begin{array}{l}\text { Estudo comparativo sobre } \\
\text { superdotação com famílias } \\
\text { em } \\
\text { socioeconômica } \\
\text { desfavoreciduão }\end{array}$ & $\begin{array}{l}\text { Chagas e Fleith } \\
(2009)\end{array}$ & $\begin{array}{l}\text { Descrever e comparar } \\
\text { características familiares que } \\
\text { favorecem o desenvolvimento dos } \\
\text { comportamentos de superdotação. }\end{array}$ & $\begin{array}{l}14 \text { alunos superdotados, } 14 \\
\text { alunos não superdotados } \\
\text { e } 28 \text { genitores. }\end{array}$ \\
\hline $\begin{array}{l}\text { Identificando adolescentes } \\
\text { de rua com potencial para } \\
\text { altas } \\
\text { superdotação }\end{array}$ & $\begin{array}{l}\text { Cardoso e Becker } \\
\text { (2014) }\end{array}$ & $\begin{array}{l}\text { Investigar } \quad \text { adolescentes em } \\
\text { situação de rua com potencial } \\
\text { para Altas } \\
\text { Superdotação. }\end{array}$ & $\begin{array}{l}4 \text { adolescentes com } \\
\text { dificuldades econômicas e } \\
\text { sociais }\end{array}$ \\
\hline $\begin{array}{l}\text { É possível encontrar } \\
\text { talentos nas ruas } \\
\text { e em instituições } \\
\text { prisionais? }\end{array}$ & Becker (2014) & $\begin{array}{l}\text { Identificar talentos em populações } \\
\text { que estão excluídas dos } \\
\text { programas de atendimento para } \\
\text { altas habilidades no Brasil, mas } \\
\text { que estiveram ou ainda estão } \\
\text { envolvidos com o sistema escolar. }\end{array}$ & $\begin{array}{l}\text { Trata-se de uma revisão de } \\
\text { literatura. }\end{array}$ \\
\hline $\begin{array}{l}\text { Talento académico, } \\
\text { vulnerabilidad escolar y } \\
\text { resultados en la prueba de } \\
\text { selección universitaria }\end{array}$ & $\begin{array}{l}\text { Adonis, Clavel } \\
\text { Boyanova (2017) }\end{array}$ & $\begin{array}{l}\text { Analisar a relação existente entre } \\
\text { o potencial de talento acadêmico, } \\
\text { as habilidades cognitivas e a } \\
\text { participação em um programa de } \\
\text { talentos. }\end{array}$ & $\begin{array}{l}1303 \text { estudantes que } \\
\text { terminaram o } 5^{\circ} \text { básico do } \\
\text { Programa PentaUC }\end{array}$ \\
\hline
\end{tabular}

Fonte: Autores (2020).

O Quadro 1 expõe os posicionamentos de Chagas e Fleith (2009) e de Adonis, Clavel e Boyanova (2017), pois são similares quando afirmam que as expectativas familiares a respeito dos filhos influenciam no desenvolvimento das altas habilidades, porém, Cardoso e Becker (2014) e Becker (2014) afirmam sobre os riscos sociais e o desenvolvimento das altas capacidades parecem ser mais otimistas que o de Adonis, Clavel e Boyanova (2017), quando pontuam o risco de desenvolver talentos em meios vulneráveis.

Especificamente sobre as expectativas familiares e os sujeitos vulneráveis, Chagas e Fleith (2009) colocam que um ambiente familiar enriquecido e organizado de modo a atender as demandas e interesses das pessoas com altas habilidades, a posição especial na família, os valores, as expectativas parentais relacionadas à educação e ao desempenho acadêmico contribuem para um melhor desenvolvimento do potencial dos filhos. As mencionadas autoras pontuam que riscos sociais não impossibilitam a manifestação de potencialidades, sendo justamente o oposto, um contexto tão adverso pode ser utilizado no desenvolvimento do potencial, desde que esse potencial seja reconhecido, aceito e valorizado e, sugerem a retirada de estereótipo da marginalização e debilidades para considerar aspectos saudáveis nesses grupos.

Ainda sobre as expectativas familiares e os sujeitos vulneráveis, Adonis, Clavel e Boyanova (2017, p.172) pontuam “quando os catalizadores não são adequados, a probabilidade de não desenvolver o talento acadêmico aumenta". De acordo com esses autores, estudantes vulneráveis e com baixos recursos econômicos também estão expostos a não desenvolver seus talentos, e, não por insuficiência de recursos, mas porque em seu meio familiar e comunitário não se tem expectativas a respeito de sua possibilidade de alcançar um nível superior ou ser bem-sucedido academicamente.

Pode-se perceber na pesquisa de Cardoso e Becker (2014) que é possível encontrar altas capacidades em meios vulneráveis, já que todos os sujeitos identificados em sua pesquisa, quais sejam em situação de rua e de dependência química, 
apresentavam potencial para habilidades artísticas, gráficas e estilo criativo. Além de pontuarem que os principais fatores de risco e proteção ao desenvolvimento de suas potencialidades referiam-se à situação socioeconômica, condições e mudanças de moradia, relacionamento social, familiar, drogas, traços de personalidade e ambiente escolar.

Assim, como salienta Becker (2014), mesmo em locais de riscos, desvantagens e perigos, em que vivem a imensa percentagem da população pobre do Brasil, encontrar crianças, adolescentes e jovens, que demonstram algum talento, é vislumbrar uma realidade mais promissora. Para ela, conseguir se sobressair positivamente em contextos desfavoráveis comprova o potencial da pessoa ao enfrentar os inúmeros fatores negativos no seu cotidiano.

Em seguida, dispõem-se os resultados das buscas em bases internacionais:

Quadro 2. Artigos Encontrados - Bases Internacionais.

\begin{tabular}{|c|c|c|c|}
\hline Título & Autor(es) & Objetivo(s) & Participante(s) \\
\hline $\begin{array}{l}\text { Sources of Talent Loss } \\
\text { among High-Achieving } \text { Poor } \\
\text { Students. Report No. } 23\end{array}$ & $\begin{array}{l}\text { Jordan e Plank } \\
(1998)\end{array}$ & $\begin{array}{l}\text { Explicar outras possíveis fontes de } \\
\text { perda de talentos }\end{array}$ & $\begin{array}{l}\text { Oito entrevistas em profundidade } \\
\text { com orientadores de um distrito } \\
\text { escolar urbano empobrecido }\end{array}$ \\
\hline $\begin{array}{l}\text { The Coincidence of } \\
\text { Depression and High Ability } \\
\text { in Delinquent Youth }\end{array}$ & $\begin{array}{l}\text { Messier e Ward } \\
(1998)\end{array}$ & $\begin{array}{l}\text { Descrever a incidência e } \\
\text { coincidência de depressão e alta } \\
\text { capacidade em uma amostra da } \\
\text { população jovem delinquente } \\
\text { encarcerada da Virgínia. }\end{array}$ & $\begin{array}{l}207 \text { jovens encarcerados foram } \\
\text { avaliados com as Matrizes } \\
\text { Progressivas Avançadas de Raven } \\
\text { e o Inventário de Depressão } \\
\text { Infantil (CDI) }\end{array}$ \\
\hline $\begin{array}{l}\text { Can the Brigance K \& } 1 \\
\text { Screen } \\
\text { Cognitive/Academic } \\
\text { Giftedness When Used with } \\
\text { Preschoolers rom } \\
\text { Economically Disadvantaged } \\
\text { Backgrounds? }\end{array}$ & $\begin{array}{l}\text { Mantzicopoulos } \\
(2000)\end{array}$ & $\begin{array}{l}\text { Verificar a precisão da tela } \\
\text { Brigance } K \& 1 \text { na identificação } \\
\text { precoce de crianças Head Start } \\
\text { com possível talento cognitivo/ } \\
\text { acadêmico }\end{array}$ & 134 crianças \\
\hline $\begin{array}{l}\text { High Ability, Rural, and } \\
\text { Poor: Lessons from Project } \\
\text { Aspire and Implications for } \\
\text { School Counselors }\end{array}$ & $\begin{array}{l}\text { Cross e Burney } \\
(2005)\end{array}$ & $\begin{array}{l}\text { Relatar uma análise das ideias e } \\
\text { experiências } \\
\text { durante as longas sessões de } \\
\text { treinamento com } 21 \text { conselheiros } \\
\text { escolares. }\end{array}$ & $\begin{array}{l}21 \text { conselheiros escolares que } \\
\text { trabalham em } 14 \text { corporações } \\
\text { escolas rurais através de um estado } \\
\text { com significativa incidência da } \\
\text { pobreza }\end{array}$ \\
\hline $\begin{array}{l}\text { Resilience and Coping: } \\
\text { Implications for Gifted } \\
\text { Children and Youth at Risk }\end{array}$ & $\begin{array}{l}\text { Kitano e Lewis } \\
(2005)\end{array}$ & $\begin{array}{l}\text { Resumir as descobertas da } \\
\text { literatura de resiliência relevante } \\
\text { para o desenvolvimento de } \\
\text { crianças e jovens e deriva } \\
\text { estratégias específicas para } \\
\text { melhorar os resultados de crianças } \\
\text { e jovens sobredotados com maior } \\
\text { risco de encontrar adversidades. }\end{array}$ & - \\
\hline $\begin{array}{l}\text { Critical Differentiation and } \\
\text { the Twice Oppressed: Social } \\
\text { Class and Giftedness. }\end{array}$ & $\begin{array}{l}\text { Latz e Adams } \\
(2011)\end{array}$ & $\begin{array}{l}\text { Pensar sobre o ensino de jovens } \\
\text { talentosos desfavorecidos. }\end{array}$ & - \\
\hline $\begin{array}{l}\text { Developing Social Giftedness } \\
\text { in Disadvantaged Girls at an } \\
\text { Indian School }\end{array}$ & Sharma (2012) & $\begin{array}{l}\text { Descrever interações de } \\
\text { desenvolvimento com um grupo de } \\
\text { alunas de uma escola pública } \\
\text { indiana situada em uma seção } \\
\text { desfavorecida da comunidade. }\end{array}$ & Alunas de uma escola pública. \\
\hline $\begin{array}{l}\text { How Prepared Are } \\
\text { Subgroups of Texas Students } \\
\text { for College-Level Reading: } \\
\text { Applying a Lexile[R]-Based } \\
\text { Approach. REL Technical } \\
\text { Brief. REL 2012-No. 018 }\end{array}$ & $\begin{array}{l}\text { Wilkins et al } \\
(2012)\end{array}$ & $\begin{array}{l}\text { Avaliar a disponibilidade de leitura } \\
\text { para subgrupos de alunos. }\end{array}$ & $\begin{array}{l}\text { Alunos da } 11^{\mathrm{a}} \text { série que fizeram a } \\
\text { avaliação anual do estado do Texas }\end{array}$ \\
\hline $\begin{array}{lr}\text { Socioeconomic } & \text { Inequality } \\
\text { and Giftedness: } & \text { Suppression }\end{array}$ & Ambrose (2013) & $\begin{array}{l}\text { Fornecer recomendações para } \\
\text { tentar contrariar alguns dos efeitos }\end{array}$ & - \\
\hline
\end{tabular}




\begin{tabular}{|c|c|c|c|}
\hline $\begin{array}{l}\text { and Distortion of High } \\
\text { Ability. }\end{array}$ & & $\begin{array}{l}\text { mais perniciosos da crescente } \\
\text { desigualdade no talentoso }\end{array}$ & \\
\hline $\begin{array}{l}\text { Exploring the Views of } \\
\text { Parents of High Ability } \\
\text { Children Living in Relative } \\
\text { Poverty }\end{array}$ & $\begin{array}{l}\text { Koshy et al } \\
(2013)\end{array}$ & $\begin{array}{l}\text { Explorar o apoio que esses pais } \\
\text { receberam e qual apoio eles } \\
\text { sentiram e precisavam para } \\
\text { promover } \\
\text { desenvolvimento e a realização de } \\
\text { seus filhos }\end{array}$ & $\begin{array}{l}21 \text { pais com crianças de } 14 \text { a } 16 \\
\text { anos identificadas como "dotadas e } \\
\text { talentosas" por suas escolas }\end{array}$ \\
\hline $\begin{array}{l}\text { Is There a Gifted Gap? } \\
\text { Gifted Education in High- } \\
\text { Poverty Schools }\end{array}$ & $\begin{array}{l}\text { Yaluma, Tyner e } \\
\text { Thomas (2018) }\end{array}$ & $\begin{array}{l}\text { Verificar se existe uma lacuna de } \\
\text { talentos nas escolas de alta } \\
\text { pobreza. }\end{array}$ & $\begin{array}{l}\text { Dados de nível escolar nos níveis } \\
\text { estadual e nacional }\end{array}$ \\
\hline 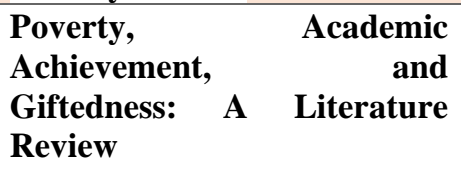 & $\begin{array}{l}\text { Olszewski- } \\
\text { Kubilius e } \\
\text { Corwith (2018) }\end{array}$ & $\begin{array}{l}\text { Revisar a literatura sobre a pobreza } \\
\text { e a identificação e os serviços } \\
\text { específicos para crianças } \\
\text { superdotadas de baixa renda. }\end{array}$ & - \\
\hline $\begin{array}{l}\text { Gifted 'in the ' Hood: Gender } \\
\text { and Giftedness as Predictors } \\
\text { of Social Risk among Low- } \\
\text { Income Students }\end{array}$ & $\begin{array}{l}\text { Bolland et al } \\
(2018)\end{array}$ & $\begin{array}{l}\text { Explorar trajetórias de } \\
\text { comportamento agressivo (ou seja, } \\
\text { porte de armas) de jovens } \\
\text { empobrecidos e talentosos. }\end{array}$ & $\begin{array}{l}\text { Meninos e meninas com e sem } \\
\text { talento. }\end{array}$ \\
\hline $\begin{array}{l}\text { A Comparison of Perceptions } \\
\text { of Barriers to Academic } \\
\text { Success Among High-Ability } \\
\text { Students From High- and } \\
\text { Low-Income Groups: } \\
\text { Exposing Poverty of a } \\
\text { Different Kind. }\end{array}$ & $\begin{array}{l}\text { Cross et al } \\
(2018)\end{array}$ & $\begin{array}{l}\text { Expor as barreiras percebidas pelos } \\
\text { estudantes para o sucesso } \\
\text { acadêmico. }\end{array}$ & $\begin{array}{l}14 \text { entrevistas com grupos focais } \\
\text { com estudantes de alta capacidade } \\
\text { da sexta à oitava série do ensino } \\
\text { médio de famílias de alta e baixa } \\
\text { renda }\end{array}$ \\
\hline
\end{tabular}

Fonte: Autores (2020).

É possível perceber um número maior de artigos na perspectiva internacional. Há um total de 9 (nove) das 14 produções encontradas, sobre altas capacidades em meios pobres ou desfavorecidos. Assim, visando demonstrar explicitamente o que esses artigos abordam, a Figura 2 demonstra os achados.

Figura 2. Temas Explorados na Relação Altas Capacidades e Pobreza.

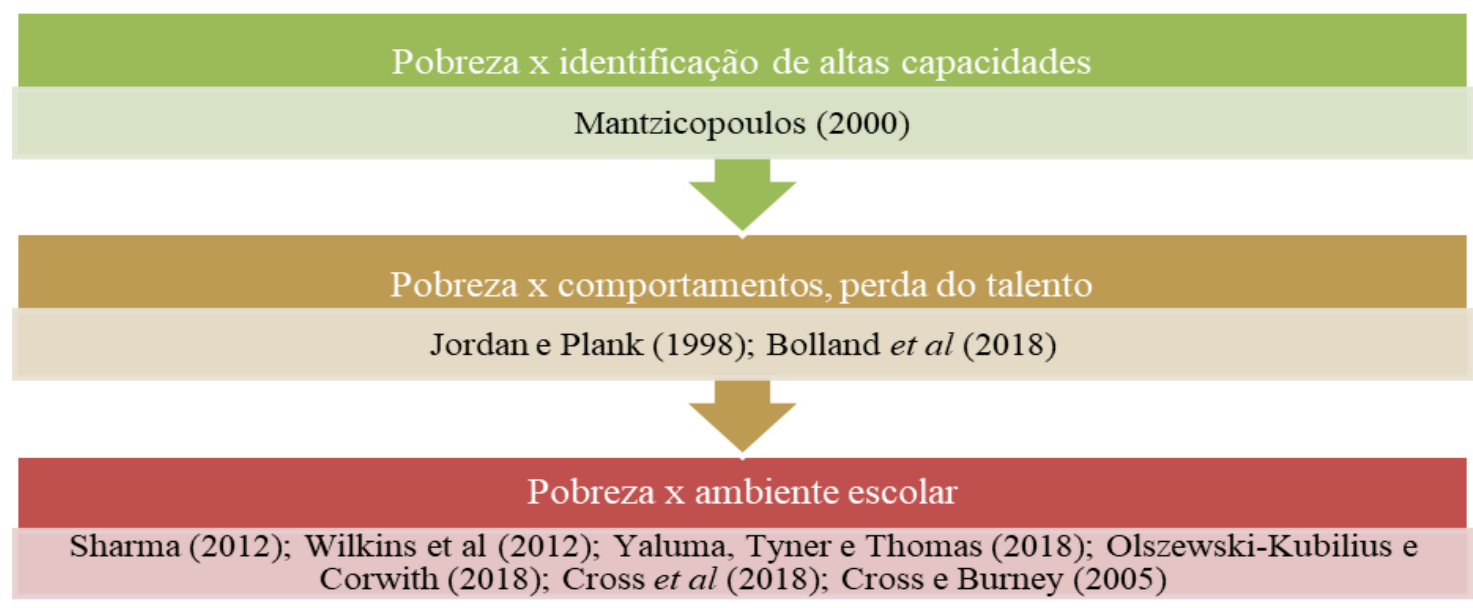

Fonte: Autores (2020).

Pode-se notar que, explicitamente, no âmbito da identificação de pessoas com altas capacidades em situação de pobreza, apenas o artigo de Mantzicopoulos (2000) abordou o tema e identificou 13 crianças com altas capacidades de famílias desfavorecidas, comprovando que há potencialidades elevadas em meios sociais desfavorecidos.

Quanto ao tema da perda do talento em pessoas pobres, somente o artigo de Jordan e Plank (1998) discute o assunto 
ao salientar que os desafios envolvidos no financiamento do ensino superior contribuem parcialmente para a perda de talentos e sua difusão entre os alunos pobres. Nesta vertente, quanto ao comportamento de pessoas pobres com altas capacidades, o artigo de Bolland et al (2018) abordou sobre a vulnerabilidade no aspecto da pobreza e explora os comportamentos agressivos de jovens empobrecidos e com altas capacidades, concluindo que as diferenças pontuadas nos resultados podem ser explicadas, examinando-se as trajetórias de impulsividade e temperamento que o jovem com altas capacidades apresenta.

Já os artigos que relacionam o aspecto escolar, a pobreza e as altas capacidades eram a maioria, sendo que o artigo Sharma (2012) se encaixa, pois, teve como foco o desenvolvimento de meninas carentes economicamente e as suas altas capacidades no contexto escolar indiano. A pesquisa de Wilkins et al (2012) buscou demonstrar o nível de leitura de estudantes com altas capacidades de meio desfavorecidos e pode concluir que apresentavam mais dificuldades e menos preparados. A pesquisa de Yaluma, Tyner e Thomas (2018) buscou abordar como as escolas muito pobres se organizam para atender as altas capacidades. Com o mesmo foco, o estudo de Olszewski-Kubilius e Corwith (2018) retrata uma revisão de literatura ao abordar os efeitos da pobreza sobre o desempenho acadêmico, sobre a identificação e os serviços específicos para estudantes com altas capacidades. Por sua vez, o trabalho de Cross et al (2018) referiu-se às barreiras do sucesso acadêmico entre alunos de classe alta e baixa com altas capacidades, demonstrando que os alunos do grupo de baixa renda descreveram o caos em suas escolas, o que interferiu significativamente no aprendizado.

Ainda sobre o aspecto escolar, o artigo de Cross e Burney (2005) trata sobre um projeto com conselheiros escolares de crianças com altas capacidades de meios rurais e pobres, concluindo que o papel do conselheiro da escola é muito importante, pois, podem ter que educar e convencer a família do potencial e das oportunidades do filho, auxiliando-o a libertar das restrições esmagadoras da pobreza rural e das altas capacidades.

Outros 5 (cinco) artigos foram encontrados nas bases de dados internacionais. Diferente das demais produções, a pesquisa de Messier e Ward (1998) trabalhou com um público encarcerado, visando perceber a relação entre depressão e altas capacidades nesses jovens. Já Koshy et al (2013) concluiu que os pais de crianças com altas capacidades de meios vulneráveis sentiam que seus conhecimentos e experiências eram escassos para ajudar seus filhos na escolha de assuntos diversos e para aconselhar sobre o ensino superior.

Kitano e Lewis (2005) abordaram uma importante discussão sobre resiliência e enfrentamento em crianças com altas capacidades em risco. Para os citados autores, o ponto central da compreensão da literatura é o conceito de que quatro tipos de fatores influenciam a resiliência, quais sejam: fatores compensatórios, de risco, de proteção e de vulnerabilidade, concluindo que a inteligência parece influir sobre a resiliência de pessoas com altas capacidades, principalmente quanto à solução e enfrentamento de problemas.

A pesquisa de Latz e Adams (2011) traz uma revisão teórica com uma proposta sobre o que ele chama de duas vezes oprimido, sugerindo que é possível que as crianças sejam oprimidas com base na categoria social e na classificação de altas capacidades, como no caso da criança com dificuldades nas salas de aula por apresentar dislexia e altas capacidades. A criança duas vezes oprimida pode lutar contra a pobreza e as altas capacidades, por exemplo.

E por fim, a produção de Ambrose (2013), apesar de ser uma revisão teórica, tratou de temas importantes a respeito do quanto a desigualdade pode afetar o desenvolvimento da alta capacidade no sujeito. Pontua, também, que a desigualdade pode distorcer as aspirações dos jovens, estimulando-os a empregar os seus talentos consideráveis para propósitos egoístas, até mesmo antiéticos ou vaidosos. Considera, todavia, que se estudiosos e profissionais conseguissem desenvolver a consciência do problema e trabalhar para neutralizar os efeitos nocivos estarão incentivando o talentoso para buscar as formas mais promissoras de auxiliar o mundo. 


\section{Discussão}

Nos resultados encontrados, tanto no âmbito brasileiro quanto internacional, pode-se perceber que pesquisas com públicos vulneráveis estão sendo realizadas. Apesar de ainda serem poucos estudos, 4 (quatro) no Brasil e 14 em bases internacionais, eles se relacionam a temas diversos e importantes sobre vulnerabilidade, tais como: pobreza, encarcerados ou que cometem atos infracionais, em situação de rua, em vulnerabilidade escolar ou em risco social. Cabe salientar que o tema mais abordado nos artigos encontrados foi a relação entre altas capacidades e pobreza.

Neste sentido, é possível perceber similaridade entre as buscas nacionais e internacionais, sendo que Chagas e Fleith (2009) aborda sobre altas capacidades em meios pobres no Brasil e Jordan e Plank (1998), Mantzicopoulos (2000), Cross e Burney (2005), Sharma (2012), Wilkins et al (2012), Yaluma, Tyner e Thomas (2018), Cross et al (2018), Olszewski-Kubilius e Corwith (2018) e Bolland et al (2018) reportam sobre o mesmo tema em meios internacionais.

O documento Saberes e Práticas da Inclusão (Brasil, 2006) ressalta haver preocupação constante com alunos com altas capacidades, a fim de que não sejam subaproveitados e deixem de dar suas contribuições sociais à coletividade e a si próprios, compartilhando suas habilidades e talentos com todos. Assinala, sobretudo, que há uma preocupação ainda maior para os alunos com altas capacidades dos meios sociocultural e econômico desprivilegiados, pois os que são pobres têm as ideias, mas, não têm escola e instrumentos para realiza-las e ofertá-las ao seu grupo social. Eles podem, contudo, assumir um comportamento mais agressivo ou rebelde quando não têm o reconhecimento social de suas potencialidades, e, consequentemente, são subaproveitados.

Em referência ao termo duas vezes oprimido citado na pesquisa de Latz e Adams (2011), Sodré (2019) concorda com Latz e Adams (2011) ao argumentar que sujeitos com altas capacidades são vulneráveis, pois sofrem por omissões e por ações, sendo a principal omissão a falta de atendimento educacional adequado, pontuando que a vulnerabilidade é inerente nas pessoas com altas capacidades, porque suas necessidades são frequentemente ignoradas e com consequências negativas.

Pode-se verificar, também, similaridade com o tema da família de pessoas com altas capacidades, sendo que o artigo encontrado de Chagas e Fleith (2009) e de Koshy et al (2013) referem-se à mesma temática, assim como os trabalhos de Becker (2014) e Messier e Ward (1998) tratam de público encarcerado, sendo um estudo realizado no Brasil e outro à nível internacional.

Os quatro estudos encontrados no Brasil demonstram que as altas habilidades estão sendo exploradas nas áreas: da família, identificação e na relação para acesso ao ensino superior, já os quatorze encontrados em âmbito internacional abordam especificamente sobre: pobreza, comportamentos, sucesso acadêmico, identificação, família, depressão, entre outros. Cabe ressaltar que duas pesquisas tratam de temas de grande contribuição para a área, são elas: a perda de talento, de Ambrose (2013) e a resiliência e enfrentamento, de Kitano e Lewis (2005). Com esse levantamento, pode-se concluir que as altas capacidades existem em todas as camadas sociais e culturais, sem distinção de raça ou credo, mas, o que não se sabe é o porquê da existência de poucos estudos relacionados a esse tema disponíveis nas bases de dados.

Quanto à resiliência, Neihart (2006) coloca que há características comuns entre as pessoas com altas capacidades e as resilientes, assim como pontuado por Becker (2014) e Kitano e Lewis (2005). Para Neihart (2006), essas características seriam a compaixão pelos outros, senso de humor, persistência frente a falhas, convicção moral ou forte código de ética, interesse em espiritualidade ou religião, maneiras respeitosas, capacidade de chamar atenção em forma positiva, habilidade para planejar para o futuro, habilidade em resolver problemas, sentimento de autonomia, possuir uma visão positiva da vida, acreditar que o esforço próprio pode mudar as coisas, interesse em desenvolver um talento especial ou um hobby e flexibilidade nos papéis de gênero.

Importa ressaltar que há similaridade entre as ideias de Ambrose (2013) encontradas nas bases internacionais e Adonis, Clavel e Boyanova (2017), citados no levantamento no Brasil, ao demostrar que o meio social pode prejudicar o 
desenvolvimento das pessoas com altas capacidades, inclusive ser confundidas por comportamentos egoístas, antiéticos ou vaidosos, ou nem mesmo ser reconhecidas pela sua família e comunidade.

Neste sentido, segundo as autoras Winner (1998) e Virgolim (2007) o meio social traz influências às altas capacidades. Winner (1998) afirma que as altas capacidades são oriundas da presença de dois fatores: as predisposições biológicas apresentadas por alguns indivíduos e os estímulos advindos do ambiente social, que culminam prematuramente no desenvolvimento de uma ou mais habilidades. E, segundo Virgolim (2007), o biológico ou genético e o meio ambiente ou meio social também influenciam na construção das altas capacidades.

Como meio de comparação aos poucos estudos encontrados, no âmbito brasileiro, uma pesquisa de Souza e Tassinari (2017), que teve como objetivo levantar e analisar estudos nas bases de dados Scientific Eletronic Library Online (Scielo) e Banco de Teses e Dissertações da Capes, entre 1995 a 2016 que abordassem a temática de altas habilidades em grupos de vulnerabilidade social, resultou em poucos estudos sobre altas capacidades e vulnerabilidade social ou grupo de risco. Os estudos encontrados por elas buscaram identificar essa população em contextos de situação de rua, camadas populares, reclusos e autores de atos infracionais, e, ainda, um estudo trouxe a visão dos profissionais de uma instituição de acolhimento sobre as altas habilidades. $\mathrm{O}$ fato de existir pessoas com altas capacidades em meios vulneráveis vem ao encontro da quebra de paradigmas e mitos socialmente construídos, um deles fortemente instituído que há a inteligência somente nas camadas sociais mais abastadas (Souza \& Tassinari, 2017).

As reflexões dessas autoras inferem escassez de estudos sobre o tema, assim como os resultados deste levantamento sistemático, apesar do recorte temporal maior de buscas e abranger somente artigos científicos.

Também, a pesquisa de Pedro e Chacon (2015) demonstrou que, das 70 teses encontradas nas bases Biblioteca Digital Brasileira de Teses e Dissertações e a Base de Datos de Tesis Doctorales (TESEO), vinte (20) eram brasileiras e cinquenta (50) espanholas e das categorias elencadas as teses foram dividas nos temas: Identidade, Identificação e Avaliação. Pode-se observar a ausência de uma categoria que abarcasse altas capacidades e vulnerabilidade. Os citados autores asseveram que foram encontradas 34 teses na Base de Datos de Tesis Doctorales (TESEO). Os temas mais predominantes foram: identificação, professores, aspectos emocionais, talento matemático e criatividade. A identificação apareceu em $30 \%$ das teses encontradas, desta forma, foi possível concluir que, apesar das teses explorarem temas diversos, bem específicos e importantes para as altas capacidades e vulnerabilidade social não são exploradas em teses espanholas.

Tendo essas pontuações, há de se concordar com Becker (2010) ao salientar que quando se conhece os locais onde vivem as pessoas comumente se foca nos riscos, desvantagens e perigos da imensa percentagem da população pobre do país. Encontrar crianças, adolescentes e jovens, que demonstram algum talento é vislumbrar uma realidade mais promissora e auspiciosa, sobretudo conseguir se sobressair positivamente em contextos desfavoráveis comprova que a pessoa possui um potencial a ser desenvolvido ao enfrentar os inúmeros fatores negativos no seu cotidiano.

\section{Conclusão}

Esta pesquisa teve o objetivo de verificar e analisar artigos científicos sobre altas capacidades em meios vulneráveis por meio de uma revisão sistemática em bancos de dados. Tal objetivo foi atingido e artigos nacionais e internacionais sobre o tema foram encontrados, mas, apesar disso, pode-se perceber que, a temática de altas capacidades e vulnerabilidade é pouco estudado. Nos artigos encontrados, vislumbrou-se que alguns temas são mais abordados nas pesquisas que outros, como por exemplo, há mais pesquisas com o público pobre que com público encarcerado ou em situação de rua.

Porém, com a presente pesquisa pode-se perceber que trabalhar com a identificação e atendimento de altas capacidades em público vulnerável, quais sejam: situação de pobreza, situação de marginalização e/ou situação de reclusão é em si um grande desafio, porém como demonstrado nas pesquisas encontradas, existem pessoas que se destacam por sua 
capacidade nesses meios.

Vale mencionar que, as crianças e adolescentes em vulnerabilidade já estão marcadas socialmente pela indiferença, o ato de buscar reconhecer seus talentos é remar contra a maré do preconceito, é tentar ir além do que estipularam como a realidade desse sujeito, é no mínimo um sinal de interesse e esperança, para que se possa olhar esse indivíduo para além do que se está aparente.

É difícil mensurar quando fracassamos em não apoiarmos o desenvolvimento das crianças e jovens com altas capacidades, especialmente os que são vulneráveis, pois, não temos como medir a perda social da falta de identificação de possíveis talentos.

Aponta-se que a presente pesquisa apresenta fragilidades, pois, no Brasil, ao limitar o estudo a três bases de dados e, somente a artigos, não houve possibilidades de abrangência a outras produções como teses, dissertações e trabalhos em anais de eventos, contudo, em âmbito internacional poderia ter sido exploradas outras possibilidades de buscas.

Espera-se, que a pesquisa possa contribuir para futuros estudos sobre a temática de altas capacidades em meios vulneráveis, mais especificamente em instituições de acolhimento, em situação de pobreza, encarcerados e marginalizados, para que seja possível apoiar o desenvolvimento do potencial das pessoas extremamente despercebidas por seus potenciais.

\section{Agradecimentos}

Agradecimentos pelo financiamento da Fundação de Amparo à Pesquisa do Estado de São Paulo (FAPESP) processo n 2017/05320-4 e em parte pela Coordenação de Aperfeiçoamento de Pessoal de Nível Superior - Brasil (CAPES) Código de financiamento.

\section{Referências}

Adonis, P. G., Clavel, V. A, \& Boyanova, D. (2017). Talento académico, vulnerabilidad escolar y resultados en la prueba de selección universitaria. Revista Estudios Pedagógicos, 43(1), 171-191. https://dx.doi.org/10.4067/S0718-07052017000100011.

Ambrose, D. (2013). Socioeconomic inequality and giftedness: Suppression and distortion of high ability. Roeper Review, 35(2), 81-92. http://search.ebscohost.com.accedys2.bbtk.ull.es/login.aspx ?direct=true\&db=a9h\&AN=86689067\&lang=es\&site=ehost-live.

Becker, M. A. A. (2013, março). É possível encontrar talentos nas ruas e em instituições prisionais. Anais do I Congresso Internacional sobre Altas Habilidades/Superdotação, IV Encontro Nacional do ConBraSD e IV Seminário de Altas Habilidades/Superdotação da UFPR. Curitiba, PR, Brasil.2010. http://conbrasd.org/wp/wp-content/uploads/2013/03/Anais-VF1.pd.

Becker, M. A. A. (2014). É possível encontrar talentos nas ruas e em instituições prisionais? Revista Educação Especial, 27(50), 689-698. https://periodicos.ufsm.br/educacaoespecial/article/view/14321/pdf.

Bolland, A. C., Tomek, S. E., Besnoy, K. D. \& Bolland, J. M. (2018). Gifted 'in the ' hood: Gender and giftedness as predictors of social risk among low-

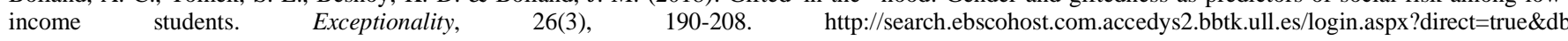
$=$ eric $\& \mathrm{AN}=\mathrm{EJ} 1170848 \&$ lang=es\&site=ehost-live.

Brasil. (2006). Saberes e práticas da inclusão: avaliação para identificação das necessidades educacionais especiais. Brasília: MEC, Secretaria de Educação Especial, 2006. http://portal.mec.gov.br/seesp/arquivos/pdf/avaliacao.pdf.

Brasil. (2008). Política nacional de educação especial na perspectiva da educação inclusiva. MEC: SEEP. http://portal.mec.gov.br/arquivos/pdf/politicaeducespecial.pdf.

Brasil. (2013). Lei n. 12.796, de 4 de abril de 2013: altera a Lei n. 9.394 de 20 de dezembro de 1996, que estabelece as diretrizes e bases da educação nacional, para dispor sobre a formação dos profissionais da educação e dar outras providências. Brasília: Planalto Central. http://www.planalto.gov.br/ccivil_03/_ato2011-2014/2013/lei/112796.htm.

Cardoso, A. O. G., \& Becker, M. A. A. (2014). Identificando adolescentes de rua com potencial para altas habilidades/superdotação. Revista Brasileira Educação Especial, 20(4), 605-614. http://www.scielo.br/scielo.php?script=sci_arttext\&pid=S1413-65382014000400011.

Chagas, J. F., \& Fleith, D. S. (2009). Estudo comparativo sobre superdotação com famílias em situação socioeconômica desfavorecida. Revista Brasileira Educação Especial, 15(1), 155-170. http://www.scielo.br/scielo.php?pid=S1413-65382009000100011\&script=sci_abstract\&tlng=pt.

Cross, J, R., Frazier, A. D., Kim, M., \& Cross, T. L. (2018). A comparison of perceptions of barriers to academic success among high-ability students from high- and low-income groups: Exposing poverty of a different kind. Gifted Child Quarterly, 62(1), 111-129. http://search.ebscohost.com.accedys2.bbtk.ull.es/login.aspx?direct=true\&db=a9h\&AN=126762157\&lang=es\&site=ehost-live. 
Cross, T. L., \& Burney, V. H. (2005). High ability, rural, and poor: Lessons from project aspire and implications for school counselors. Journal of Secondary Gifted Education, 16(4), 148-156. http://search.ebscohost.com.accedys2.bbtk.ull.es/login.aspx?direct=true\&db=eric\&AN=EJ746038\&lang=es\&site=ehostlive.

Cupertino, C. M. B. (2008.). Um olhar para as altas habilidades: Construindo caminhos. Secretaria da Educação Estudos e Normas Pedagógicas, Centro de Apoio Pedagógico Especializado. São Paulo: FDE. http://www.christinacupertino.com.br/arquivos/Altas_habilidades.pdf.

Decreto-Lei $n^{o} 10.502$ (2020). Institui a Política Nacional de Educação Especial: Equitativa, Inclusiva e com Aprendizado ao Longo da Vida. Atos do Poder Executivo. https://www.in.gov.br/en/web/dou/-/decreto-n-10.502-de-30-de-setembro-de-2020-280529948.

Jordan, W. J., \& Plank, S. B. (1998). Sources of talent loss among high-achieving poor students. Center for Research on the Education of Students Placed At Risk. http://search.ebscohost.com.accedys2.bbtk.ull.es/login.aspx?direct=true \&db=eric\&AN=ED424342\&lang=es\&site=ehost-live.

Kitano, M. K., \& Lewis, R. B. (2005). Resilience and coping: Implications for gifted children and youth at risk. Roeper Review, 27(4), 1-200. http://search.ebscohost.com.accedys2.bbtk.ull.es/login.aspx?direct=true \&db=eric\&AN=EJ726722\&lang=es\&site=ehost-live.

Koshy, V., Brown, J., Jones, D., \& Smith, C. P. (2013). Exploring the views of parents of high ability children living in relative poverty. Educational Research, 55(3), 304-320. http://search.ebscohost.com.accedys2.bbtk.ull.es/login.aspx?direct=true \&db=eric\&AN=EJ1025217\&lang=es\&site=ehost-live.

Landau, E. (2002). A coragem de ser superdotado. Arte \& Ciência.

Latz, A. O., \& Adams, C. M. (2011). Critical differentiation and the twice oppressed: Social class and giftedness. Journal for the Education of the Gifted, 34(5), 773-789. http://search.ebscohost.com.accedys2.bbtk.ull.es/login.aspx?direct=true\&db=eric\&AN=EJ942094\&lang=es\&site=ehost-live.

Lei $n^{\circ}$ 8.069/90. (2015). Edição comemorativa. Brasília: Câmara dos Deputados, Edições Câmara. https://www.camara.leg.br/internet/agencia/infograficoshtml5/estatuto_crianca/estatuto_crianca_adolescente_25anos_edcomemorativa.pdf.

Mantzicopoulos, P. Y. (2000). Can the brigance k \& 1 screen detect cognitive/academic giftedness when used with preschoolers from economically disadvantaged backgrounds? Roeper Review, 22(3), 185-91. http://search.ebscohost.com.accedys2.bbtk.ull.es/login.aspx?direct=tr $\mathrm{ue} \& \mathrm{db}=$ eric $\& \mathrm{AN}=\mathrm{EJ} 606614 \&$ lang=es \&site=ehost-live.

McCluskey, K. W., Treffinger, D. J., Baker, P. A., Wiebe, A. C., Anchan, J. P., Bergsgaard, M., Glade, L., Lamoureux, K., McCluskey, A. L. A., McCluskey, C. I., McCluskey, K. C., O’Hagan, S. C., \& Smith, T. (2016). Lost prizes: Identifying and developing the talents of marginalized populations. Outside North America.

Messier, L. P., \& Ward, T. (1998). The coincidence of depression and high ability in delinquent youth. Journal of Child \& Family Studies, 7(1), 97-105. http://search.ebscohost.com.accedys2.bbtk.ull.es/login.aspx?direct=true\&db=a9h\&AN=363684\&lang=es\&site=ehost-live

Moher, D., Liberati, A., Tetzlaff, J., \& Altman, D. G. The PRISMA Group. (2015). Preferred reporting items for systematic reviews and meta-analyses. the prisma statement. (Galvão, T. F., Pansani, T. de S. A., \& Harrad, D. Trad.) Epidemiologia e Serviços de Saúde, 24(2), 335-342. https://www.scielo.br/pdf/ress/v24n2/2237-9622-ress-24-02-00335.pdf.

Minayo, M. C. de S. (2010). O desafio do conhecimento: Pesquisa qualitativa em saúde. Hucitec-Abrasco.

Neihart, M. (2006). Building resilience in gifted children: Can resiliency be taught or is it innate? Understanding Our Gifted, 18(2), 3-6. https://eric.ed.gov/?id=EJ848380.

Pedro, K. M., \& Chacon, M. C. M. (2015). Panorama brasileiro e espanhol sobre teses de doutorado na área das altas habilidades/superdotação. Revista IberoAmericana de Estudos em Educação, 1151-1164. http://search.ebscohost.com.accedys2.bbtk.ull.es/login.aspx?direct=true\&db=a9h\&AN=113812834\&lang=es\&site=ehost-live.

Sampaio, R. F., \& Mancini, M. C. (2007). Estudos de revisão sistemática: Um guia para síntese criteriosa da evidência científica. Revista Brasileira de Fisioterapia, 11(1), 83-89. https://www.scielo.br/pdf/rbfis/v11n1/12.pdf.

Sharma, Y. (2012). Developing social giftedness in disadvantaged girls at an indian school. Gifted Education International, 28(2), 201-214. http://search.ebscohost.com.accedys2.bbtk.ull.es/login.aspx?direct=true\&db=eric\&AN=EJ967851\&lang=es\&site=ehost-live.

Simonetti, D. C., Almeida, L. S., \& Guenther, Z. (2010). Identificação de alunos com altas capacidades: Uma contribuição de indicadores neuropsicológicos. Revista Educação Especial, 23(36) 43-56. https://periodicos.ufsm.br/educacaoespecial/article/view/1633.

Sodré, M. C. (2019). Altas habilidades e grupos em situação de vulnerabilidade. In R. A. Rangni (Org.), Altas habilidades: Sugestões para pesquisadores e educadores. EdUFSCar.

Souza, A. R. S., \& Tassinari, A. M. (2017). Altas habilidades/superdotação em grupos de vulnerabilidade social: Levantamento em bases de dados brasileira. Anais do Seminário De Altas Habilidades e $2^{a}$. Mostra do Grupo de Pesquisa para o Desenvolvimento do Potencial Humano. UFSCar, São Carlos. http://anaisseminarioaltashabilidadesufscar.blogspot.com/p/edicao-atual-como-citar-seminario-de.html.

Virgolim, A. M. R. (2007). Altas habilidades/superdotação: Encorajando potenciais. Brasília: Ministério da Educação, Secretaria de Educação Especial. http://www.dominiopublico.gov.br/download/texto/me004719.pdf.

Wilkins, C., Rolfhus, E., Hartman, J., Brasiel, S., Brite, J., \& Howland, N. (2012). How prepared are subgroups of texas students for college-level reading: Applying a lexile[r]-based approach. Regional Educational Laboratory $\quad$ Southwest, 18 , http://search.ebscohost.com.accedys2.bbtk.ull.es/login.aspx?direct=true\&db=eric\&AN=ED528970\&lang=es\&site=ehost-live.

Winner, E. (1998). Crianças superdotadas: Mitos e realidades. Artes Médicas. 
Research, Society and Development, v. 10, n. 1, e22810111578, 2021

(CC BY 4.0) | ISSN 2525-3409 | DOI: http://dx.doi.org/10.33448/rsd-v10i1.11578

Yaluma, C. B., Tyner, A., \& Thomas B. F. I. (2018). Is there a gifted gap? Gifted education in high-poverty schools. Thomas B. Fordham Institute. http://search.ebscohost.com.accedys2.bbtk.ull.es/login.aspx?direct=true\&db=eric\&AN=ED592389\&lang=es\&site=ehost-live. 